\title{
DECISION THEORY WITH MULTIPLE CRITERIA: AN APPLICATION OF ELECTRE IV AND TODIM TO SEBRAE/RJ
}

\author{
Luís Alberto Duncan Rangel \\ EEIMVR / Federal Fluminense University (UFF) \\ Volta Redonda - RJ, Brazil \\ duncan@metal.eeimvr.uff.br \\ Luiz Flávio Autran Monteiro Gomes* \\ Ibmec/RJ \\ Rio de Janeiro - RJ, Brazil \\ autran@ibmecrj.br \\ Rogério Amadel Moreira \\ SEBRAE/RJ \\ Rio de Janeiro - RJ, Brasil \\ rmoreira@sebraerj.com.br \\ * Corresponding author / autor para quem as correspondências devem ser encaminhadas \\ Recebido em 11/2008; aceito em 06/2009 \\ Received November 2008; accepted June 2009
}

\begin{abstract}
This paper presents an application of two methods of Multi-Criteria Decision Analysis (MCDA), ELECTRE IV and TODIM, in order to tackle the problem of ranking projects with important economic and social consequences in the Rio de Janeiro State. These projects are ranked under the presence of quantitative and qualitative criteria. ELECTRE IV is a method of the French School of MCDA whose use does not rely on knowledge of criteria weights. TODIM, on the other hand, is a method that is based on the paradigm of Prospect Theory and that has elements of both the French and the American School of MCDA. Although ranks obtained by both methods were different, the same project was ranked as the best alternative according in both. The practical experience described in this paper has suggested that the use of MCDA methods in the ranking of project can significantly clarify the decision making process.
\end{abstract}

Keywords: decision theory; multi-criteria decision analysis; priorities of projects.

\section{Resumo}

Este artigo apresenta uma aplicação de dois métodos de Apoio Multicritério à Decisão (AMD), ELECTRE IV e TODIM, a fim de resolver um problema de ordenação de importantes projetos com conseqüências econômicas e sociais no Estado do Rio de Janeiro. Estes projetos são ordenados empregando critérios qualitativos e quantitativos. O ELECTRE IV é um método da Escola Francesa de AMD, que não utiliza peso para os critérios. O TODIM é um método que está baseado no paradigma da Teoria do Prospecto, têm elementos da Escola Francesa e Americana de AMD. Embora as ordenações de ambos os métodos sejam diferentes, um mesmo projeto foi ordenado como a melhor alternativa de acordo com ambos os métodos. A experiência prática descrita neste artigo sugere que o uso de métodos de AMD na avaliação de projetos pode, significativamente, tornar mais claro o processo decisório.

Palavras-chave: teoria da decisão; apoio multicritério à decisão; priorização de projetos. 


\section{Introduction}

Decision Theory is the field of Operations Research that covers the study of the paradigms subjacent to human decisions as well as their analytical methods. Modern Decision Theory provides a broad spectrum of analytical tools, ranging from traditional, mono-criterion decision analysis to multi-criteria decision aiding and negotiation support systems (Raiffa, 2002). An important branch of Decision Theory emerged in the seventies aiming at solving decision problems in the presence of multiple criteria. Those criteria are conflicting, quantitative as well as qualitative. This new field has been quite often named Multi-criteria Decision Analysis, or MCDA (Belton \& Stewart, 2002). This article presents the application of two methods of MCDA to the problem of selecting projects with important social and economic consequences to the State of Rio de Janeiro. The question of multi-criteria evaluation of the projects approached here is based on the SEBRAE/RJ case. SEBRAE/RJ is an institution which operates with public funds, with the aim of developing micro and small business. It is indeed a support service for micro and small business in the State of Rio de Janeiro.

At this time, Brazil is experiencing an increasing demand for transparency in decisions concerning the allocation of the resources of institutions, principally among those funded by public resources. The growing questioning by society of the efficiency involved in the application of resources may be partly answered by an investigation into the presence of suitable decision support administration methods in these institutions. In this way, analysing the institutions which carry out their activities through projects and considering that their strategic guidelines and evaluation criteria should be in line with the expectations of society, it falls to the administrator to decide the best way to prioritise the allocation of the resources of these projects.

The problem rests, therefore, in identifying, from among various methods of MCDA, the ones which best meet the needs of the decision maker in the multi-criteria evaluation process of the projects, both when adjusting the size of the projects portfolio in the face of the funding scenario and when demonstrating the performance of the projects to the managers. The methods must respect the diversity of the characteristics of the criteria and make the decision making process transparent.

The correct use of the two MCDA methods applied in this study would permit revision and improvements to the portfolio of projects, considering the diverse points of view existing in the decision process. In this way, identifying which project best reflects the desired aim would permit a greater concentration of effort and would aid in the allocation of resources, particularly at moments of scarcity.

\section{The SEBRAE/RJ case}

With penetration in all of the Rio de Janeiro State, SEBRAE/RJ has the mission of "promoting competitiveness and the sustainable development of micro and small business and encourage entrepreneurship" (SEBRAE/RJ, 2006a). There are ten strategic guidelines which direct its activities, which, due to its mission, are significantly wide-ranging. These guidelines range from "acting in an integrated, sustainable and matricial way in concentrations of economic activities and local productive arrangements, seeking to increase the scale of service" to "revolutionizing individual service" (SEBRAE/RJ, 2006b). As it forms part of a larger system which encompasses all the States, both the guidelines and the focus of activity must be in line with the Strategic Guidelines and Priorities of the SEBRAE System. 
At the moment, the Institution defines the inclusion or not of a project into its portfolio at meetings and sector committees with the participation of the Management Committee, Development Managers and representatives of the Deliberative Council. One evaluation method currently in use, and which was implemented in 2004, aims to establish a degree of adherence among the projects already chosen to the SEBRAE/RJ guidelines and the Strategic Priorities of the SEBRAE system, through a consistency analysis matrix. However, the use of this matrix does not meet all of the peculiarities which the decision maker at SEBRAE/RJ might wish to include in the context of project evaluations (SEBRAE, 2007).

In this way, the introduction of new methods which this case study approaches aims to meet a new evaluation requirement, where new criteria could be considered and old criteria would receive a form of calculation which would permit the decision makers to allocate the current form of evaluation directly to the criteria.

The two MCDA methods, ELECTRE IV (Roy \& Bouyssou, 1993) and TODIM (Gomes \& Rangel, 2009), were used in this case study in order to provide support to the SEBRAE/RJ decision making process.

\section{Characteristics of the Multi-criteria Decision Aiding Methods}

In order to deal with problems which involve various objectives simultaneously in a logical way, MCDA methods seek to go deeper along a holistic outlook, aggregating all the information available including that of a subjective nature. The purpose is to achieve greater transparency and systemization of the decision making process. The complexity of these decision moments will mean that one of the main characteristics of this methodology increases, the multidimensional representation of the problem.

Other characteristics will be joined to this characteristic, such as: the search to identify information / critical regions to analyse the decision making process; improved understanding in relation to the dimensions of the problem; acceptance of the possibility that different formulations may be valid for the same problem; acceptance of the fact that a representation of comparison between the alternatives, even though only partial, can be relevant to the making of the decision and the admission that working with explicit representations can outrank numerical representations defined artificially (Hammond, Keeney \& Raiffa, 1999).

Bouyssou et al. (2002) emphasise the need to analyse the decision as a process not as a point in time like a decree. The author states that the decision cannot be isolated from the construction of the alternatives, or from the individual and organizational context of the choice, even if it is possible to identify the moment when the decision occurred. As it is seen as a process, the analysis of the decision must not stop with the making of the choice.

According to Belton \& Stewart (2002), every decision made involves various simultaneous points of view - sometimes consciously explicit, other times not. Thus, it can be concluded that we all practice multi-criteria decision making. In this way, the objective of MCDA would be to achieve integration between objective measurements and the value judgements made by the decision agents and to manage, in this context, to explain and to administrate the subjectivity involved. In relation to this point, Goodwin \& Wright (2000) remember that, if on one hand it is never possible to eliminate the subjectivity which exists at the moment of the decision, on the other hand, making it explicit would bring greater transparency to the process. 
Following the same line of transparency and going further in the direction of decision analysis, Brown (2005) states that both the tool used and the analysis should have the purpose of permitting increased rationality on the part of the decision agent. In this way, according to the same author, a rational decision would be one where the decision agent increases his/her effective well-being and, based on all that is known, judges and feels in a logical manner. This, however, does not imply that the results of the decisions obtained will always satisfy the decision maker, as the variables are always changing.

In relation to this aspect of satisfaction with the result reached by the decision, Belton \& Stewart (2002) call attention to some myths which exist regarding the MCDA methodology: 1st) the use of MCDA will bring the right answer to each and any problem. 2nd) MCDA leads us to an objective analysis which relieves the decision makers of the responsibility of carrying out difficult judgements. 3rd) MCDA will remove the "difficulty / pain" of the decision process.

Firstly, it is important to establish that there is no "right answer", even in the context of the use of the model. The concept of "optimal solution" often present in Operational Research does not exist within the structure of MCDA.

\subsection{The American School, the French School and Hybrid Methods of MCDA}

It can be said that there are currently two great schools of study of multi-criteria methods: the American School and the French School. The origin of these schools and the technique established by each of them harks back to the first scientifically formalised and accepted works. Not only the techniques but also the actions which will be used during the decision making process are distinct.

During the 1970s, with a methodology based on the hierarchical analysis of data, the American School developed one of the first methods for multi-criteria decision making in the presence of quantitative and qualitative criteria, called the AHP (Analytic Hierarchy Process) method created by Thomas L. Saaty. Based on the hierarchical representation of objectives or criteria involved in the solving of a problem, the method seeks a global measurement for each of the alternatives through a pairwise comparison of each element at a specific hierarchical level (Saaty, 1994). Considering that in the construction of this hierarchy the alternatives are at the lowest hierarchical level, the decision agent, at the end, according to the method, should have managed to synthesise all of the values in the model and be able to prioritise or classify the alternatives.

Another method which is representative of the American School is the Multiattribute Utility Theory (MAUT), an extension of classical Utility Theory for the multiattribute context. In this sense, the method, which works using a list of attributes for each alternative, was developed largely from the contribution of Keeney \& Raiffa (1999). These two authors established the concept of measuring the utility of the solution of each of the alternatives through the construction of a mathematical function which considers all the attributes involved in the problem. These methods work with presuppositions such as the non-existence of incomparability among the alternatives and transitivity in the relations of preference and indifference (Keeney \& Raiffa, 1999).

The French School, with a proposal which contrasts with the American School, admits a more flexible model, based on a modelling of the preferences. In this, among other differences which we approached in this work, is the fact of not presuming comparability 
among the alternatives, of not needing to structure the criteria hierarchically and of not seeking a mathematical function to model the analytical support process for making the decision.

The first method of the French School was originally published by Bernard Roy in 1968. It was the first method of the ELECTRE family (where ELECTRE stands for Elimination Et Choix Traduisant la Réalité), called ELECTRE I. Later, other methods were designed following the same central theoretical concept of relationships of outranking, although each of these methods seeks to solve a different problem, using diverse inter-criteria and intra-criteria, and analysing a different quantity of outranking relationships (Roy \& Bouyssou, 1993).

There is, however, at least one method which does not make use of weights, called ELECTRE IV. According to Roy \& Hugonnard (1982) in the work which from which ELECTRE IV originated, this method would be able to solve problems using concepts such as outranking and pseudocriteria where the decision agent does not want to determine weights for the criteria. In this way, the solution is obtained by means of a sequence of grouped outranking relationships.

In addition to the ELECTRE methods, the French School contributes with another family of methods called PROMÉTHÉE (Preference Ranking Organization Method for Enrichment Evaluations). The PROMÉTHÉE method makes use of the outranking relationship through the concept of "net outranking flow" (Brans \& Mareschal, 2002).

Neverthless, other MCDA methods exist that do not fit neither in the American nor in the French School. Those are then named 'hybrid methods of MCDA'. This is for instance the situation of TODIM (Gomes \& Rangel, 2009), another method used in the SEBRAE/RJ study. According to Bouyssou et al. (2000), the choice of method must be the result of an evaluation of the parameters chosen, the type and precision of data, the way in which the decision maker thinks and his/her knowledge of the problem. What is expected to be obtained as a result, whether a selection, a ranking or a classification, will also have an influence on the decision. An important point will be the evaluation of the problematic object of the decision and the inter-criteria and intra-criteria information available. The decision analyst should be able to evaluate the convenience or not of adopting a method based on a procedure of aggregating with or without a unique synthesis criterion.

In relation to the difficulty in defining the method to be used, Ozernoy (1992) emphasised that multi-criteria decision aiding methodology has various methods which can be used for the solution of diverse problems. In this way, the choice itself of a multi-criteria decision aiding method is already a multi-criteria problem. The methods used in this SEBRAE/RJ study were based not only on the research on the existing multi-criteria analysis methods but also on meetings with the Strategies and Guidelines Area, to seek to identify the criteria and the preference/indifference thresholds which best portray the manner of evaluation with which it was desired to work. Part of the evaluation presented in this paper considered technical criteria, strictly related to the method, and another part, aspects related to the way in which the decision maker wishes to work with the decision making process. Primary data utilized in this case study were the same presented in Moreira \& Gomes (2007) and in Moreira, Gomes \& Rangel (2008).

We proceed to explaining major characteristics and justifications of the use of both ELECTRE IV and TODIM in this study. 


\subsection{The ELECTRE IV Method}

The methods of the ELECTRE family, a representative of the French School, are recommended for their greater flexibility and their differentiated positioning in relation to the concepts of transitivity and independence among the alternatives. Part of this evaluation considered technical criteria, strictly related to the method, and another part, aspects related to the way in which the decision maker wishes to work with the decision making process.

In the SEBRAE/RJ case, the first option was to analyse which of the two great MCDA Schools - the American and the French - would be most appropriate to the manner of evaluation with which the decision maker wished to work.

The analysis carried out investigated the possibility of using MAUT and the ELECTRE family methods. MAUT, however, as well as the AHP method, have characteristics which are not suitable to the case in question, as the decision maker does not intend to give weights to the decision criteria.

Initially, it was considered that transitivity is one of the main axioms needed to use MAUT. This transitivity is described below:

- Between any two alternatives a and $b$ which are being compared, one and only one of the statements is true: a) a is preferable to $\mathrm{b}, \mathrm{aPb} ; \mathrm{b}$ ) $\mathrm{b}$ is preferable to $\mathrm{a}, \mathrm{bPa}$; or c) a is indifferent to $b$, aIb.

- If a is preferable to $\mathrm{b}$ and $\mathrm{b}$ is preferable to $\mathrm{c}$, then a must be preferable to c (transitivity of preference).

- If a is indifferent to $\mathrm{b}$ and $\mathrm{b}$ is indifferent to $\mathrm{c}$, then a must be indifferent to c (transitivity of indifference).

Therefore it was concluded that a possible acceptance of transitivity in the preference relationships of the SEBRAE/RJ projects would not reflect the evaluation that the decision agents intended to implement in the Institution and would simplify the analysis in an inappropriate way.

Three other advantages of ELECTRE methods over MAUT are the following: (i) ELECTRE methods accept the notion of non-comparability among the alternatives, and with the possibility that the decision agent has a weak preference for one of the options, as can occur when using the analytical method of the French School; (ii) the possibility of using pseudocriteria, provided by some methods of the ELECTRE family, taking into account that those responsible for the decision may have difficulty in explaining clearly and unequivocally an indifference or a strict preference; and (iii) it is difficult in practice the construction of a the value function or utility function, as in terms of evaluation and abstraction, it may be difficult for the decision maker to establish the values of each alternative in terms of utility for such diverse aspects that are present in each of the nine SEBRAE/RJ criteria.

Lastly, considering that among the criteria chosen by SEBRAE/RJ to evaluate projects there are, for example, capacity to contribute to the sustainable development of the region, capacity to interact with other sectors of the economy and capacity to generate work and income -, there is some difficulty in guaranteeing that the criteria chosen would satisfy the condition of independence, which is indispensable for the use of the multiattribute additive utility function, as these criteria cover aspects which in economic terms can be considered strongly inter-related. 
During the contacts carried out it was observed that the following factors supported the choice for the ELECTRE IV method:

1st) the type of problem.

MCDA can solve various types of problems, which can be grouped in four main groups: selection, classification, ranking and description.

SEBRAE/RJ needs to use various criteria to analyse the performance of the projects present in its portfolio, and this evaluation will have to achieve their final ranking. In this way, methods which focus on selection and classification such as ELECTRE I, ELECTRE IS and ELECTRE TRI would not meet the purpose of the analysis. The same occurs with some methods of the PROMÉTHÉE family, such as PROMÉTHÉE I, III, IV and V, which would not achieve a complete pre-order, also not achieving the SEBRAE/RJ objective.

2nd) the treatment to be given to the criteria.

After several meetings with the Strategies and Guidelines Area it became clear that the Institution would not like to reflect on and deal with the criteria in a hierarchical way, or even establish the importance of one in relation to another through weights. This option not to use weights reflects a current positioning, the objective of which is to maintain a balance among the importance of the criteria which will be used to judge the projects, as the projects cover economic and social actions of diverse characteristics. It is important to clarify that the Institution acts in line with its Strategic Guidelines and Priorities from its State Deliberative Council, which contains representatives of diverse economic and social forces in the State of Rio de Janeiro, and that the scores obtained in the criteria chosen for evaluation of the projects are influenced by the area of activity in these projects. In this way, the allocation of weights would certainly bring a definition of priority to the evaluation process which is not yet intended by the State Deliberative Council / Management Committee.

This being so, AHP type methods, which work with the hierarchical order of the criteria, and others such as ELECTRE II and ELECTRE III, which use weights, would also not meet the objectives of the case in question.

3rd) the gain with the use of pseudocriteria.

As the studies were carried out, a significant point of gain identified by the Institution for the evaluation of the projects was the possibility of establishing bands of preference and indifference in each criterion. The presence, therefore, of the pseudocriteria, comes to be seen as fundamental. In this way, methods which work only with simple criteria, such as ELECTRE I and ELECTRE II, would not be among those chosen.

4th) the possibility of analysing how the outranking occurred.

The analysis of the alternatives through evaluation in terms of quantity of criteria which present outranking and the way in which the dominance occurred, would be more enriching than the evaluation of an index obtained, for example, only by the preference function.

In this way, opting for ELECTRE IV would give the decision agent the possibility to evaluate the results obtained in the comparisons between projects in an analytical way.

This type of analysis would not be possible, for example, using PROMÉTHÉE II, as the difference between preference intensities pointed out by this method cannot manage to translate the way in which this dominance occurred as well as ELECTRE IV. 
Regarding this aspect, Goodwin \& Wright (2000) reaffirm the importance of the choice of a method which makes the decision making process transparent. The transparency, according to these authors, would be related to the use of tools which permit an investigation into the steps taken by the analyst to reach the decision. The ability to trace the analysis they call the audit trail.

In this way, identifying the motives for preferring one action in relation to another would be fundamental to produce a rational defence of the option made, principally at moments when justifying to third parties. The choice of the method therefore is made according to its capacity to provide argumentation.

It was therefore concluded that, in the current situation for SEBRAE/RJ, the more analytical and deeper understanding provided by ELECTRE IV, in its outranking evaluation, would make the decision richer in terms of argumentation.

\subsection{The TODIM Method}

The TODIM method was conceived principally to resolve problems concerning the ranking of alternatives considering standards of preferences when decisions are made in the presence of multiple criteria and when dealing explicitly with the perceptions of risk associated with each of these criteria. This method therefore combines a multi-criteria focus and Prospect Theory (Kahneman \& Tversky, 1979), characterized by: (i) being a tool which is technically accessible even to professionals without a solid analytical background in MCDA; (ii) providing a ranking from which the recommended decision will be produced; (iii) encompassing quantitative and qualitative criteria; (iv) ranking criteria hierarchically; and (v) dealing with the interdependence among criteria. The method consists of a constructivist approach, as the solution to the problem is formulated through interactions and contains the following main stages in its procedure: (a) pair comparisons between criteria, with the value judgments expressed, for example, by the Saaty scale (Saaty, 1994); (b) the determining of a reference criterion; (c) the valuation of the alternatives in relation to each criterion, with the performance of each criterion expressed in a scale of 0 to 10, or, alternatively, in a verbal scale; (d) the formation of a matrix of relative dominance; (e) calculation of the measurements of the global values of each alternative. The mathematical expressions (1), (2), (3), (4) and (5) constitute the modeling underlying the use of the TODIM method (Gomes \& Lima, 1992a; Gomes \& Lima, 1992b; Gomes \& Rangel, 2009).

$$
\begin{aligned}
& \delta(\mathrm{i}, \mathrm{j})=\sum_{\mathrm{c}=1}^{\mathrm{m}} \Phi_{\mathrm{c}}(\mathrm{i}, \mathrm{j}), \quad \forall(\mathrm{i}, \mathrm{j}) \\
& \Phi_{\mathrm{c}}(\mathrm{i}, \mathrm{j})= \begin{cases}\sqrt{\frac{\mathrm{a}_{\mathrm{rc}}\left(\mathrm{w}_{\mathrm{ic}}-\mathrm{w}_{\mathrm{jc}}\right)}{\sum_{\mathrm{c}} \mathrm{a}_{\mathrm{rc}}}} & \text { se } \mathrm{w}_{\mathrm{ic}}-\mathrm{w}_{\mathrm{jc}}>0 \\
0 & \text { se } \mathrm{w}_{\mathrm{ic}}-\mathrm{w}_{\mathrm{jc}}=0 \\
-\frac{1}{\theta} \sqrt{\frac{\left(\sum_{\mathrm{c}} \mathrm{a}_{\mathrm{rc}}\right)\left(\mathrm{w}_{\mathrm{jc}}-\mathrm{w}_{\mathrm{ic}}\right)}{\mathrm{a}_{\mathrm{rc}}}} & \text { se } \quad \mathrm{w}_{\mathrm{ic}}-\mathrm{w}_{\mathrm{jc}}<0\end{cases}
\end{aligned}
$$




$$
\xi=\frac{\sum_{j=1}^{n} \delta(i, j)-\min \sum_{j=1}^{n} \delta(i, j) .}{\max \sum_{j=1}^{n} \delta(i, j)-\min \sum_{j=1}^{n} \delta(i, j)}
$$

where:

$\delta_{i, j}$ - dominance measurement of an alternative i in relation to another alternative $\mathrm{j}$;

$\mathrm{a}_{\mathrm{rc}}$ - substitution rate or trade-off relationship of $\mathrm{r}$ and c criteria;

$\mathrm{w}_{\mathrm{ic}}$ and $\mathrm{w}_{\mathrm{jc}}$ - value measurements, or weights, of the alternatives $i$ and $j$ for criterion $c$;

$\theta$ - attenuation factor, used to increase the representativity of the curve adjusted to the scattering of points related to the decision agent's perception of losses; its value is empirical, tested in practice for each decision making process;

$\xi$ - desirability of each alternative.

When applying the TODIM method, at each moment the degree of partial dominance of each alternative in relation to the others is calculated by means of interactive stages. At the end of these successive calculations the utilities of the alternatives are normalized and translated into performances which vary from 0 to 1 , with the best alternative corresponding to the maximum performance, while the worst of them presents the minimum performance. The fact that the minimum performance is represented by zero, however, does not necessarily mean that the alternative has a utility equal to zero. It should be highlighted that the decision agent's perception of losses, in this modeling, is associated with an attenuation factor, representative of the degree of aversion to risk and corresponding to the maximum correlation among the points distributed in the losses and gains curve. This means that, given two different perceptions of risk, the same alternative could be passed over by one decision agent and preferred by another. The psychological foundation of the TODIM method is shown by the application of additive difference functions which vary according to the decision agent's perception of losses and gains. Thus in the equations (2), (3) and (4) it must be noted that, aligned with Prospect Theory, the relationship $\left(\mathrm{w}_{\mathrm{ic}}-\mathrm{w}_{\mathrm{jc}}\right)>0$ represents a relative gain and $\left(\mathrm{w}_{\mathrm{ic}}-\mathrm{w}_{\mathrm{jc}}\right)<0$ a relative loss. In this sense, the term wjc functions as an anchor, or in other words, the reference for gains and losses for a criterion c does not vary during the comparison between the alternatives $\mathrm{i}$ and $\mathrm{j}$; it varies only when changing the reference criterion. In this way, there will be as many calculation tables as there are criteria considered and these calculations are carried out by the equations (2), (3) and (4) for relative dominance and (5), for the normalization of the global measurements of each alternative; these measurements are called, in the TODIM method, desirabilities (Gomes \& Rangel, 2009). The scales used by the TODIM method are explained in Gomes \& Maranhão (2008) and therefore we refer the reader to this article.

\section{Case Study}

Alternative projects and evaluation criteria were selected based on the two-step process presented below:

1st Step) Defining the Alternatives - In order to carry out the definition of the alternatives, an identification of the Projects to be analysed was undertaken in conjunction with the Strategies and Guidelines Area. Eleven projects belonging to a single region in the State of Rio de Janeiro were chosen for this initial evaluation.

Pesquisa Operacional, v.29, n.3, p.577-590, Setembro a Dezembro de 2009 
2nd Step) Identification of the Criteria - In conjunction with the Strategies and Guidelines Area, 9 (nine) criteria were defined to evaluate the Projects using the ELECTRE IV method, with 2 (two) obtained through objective data and 7 (seven) based on subjective analysis, briefly explained in Tables 1, 2 and 3:

Table 1 - Objective criteria.

\begin{tabular}{|l|l|l|}
\hline $\begin{array}{l}\text { 1. Total cost of the } \\
\text { project/ Number of } \\
\text { direct beneficiaries } \\
\text { of the Project }\end{array}$ & $\begin{array}{l}\text { Cost-benefit } \\
\text { relationship - based on } \\
\text { the search to do more } \\
\text { with less. }\end{array}$ & $\begin{array}{l}\text { Form of evaluation: Calculation of the cost } \\
\text { of a project in reais (R\$ - Brazilian } \\
\text { currency) divided by the number of people } \\
\text { that will directly benefit from the project. }\end{array}$ \\
\hline $\begin{array}{l}\text { 2. Own income } \\
\text { generated / Total } \\
\text { Cost of the Project }\end{array}$ & $\begin{array}{l}\text { SEBRAE/RJ sets } \\
\text { targets to achieve its } \\
\text { own income. }\end{array}$ & $\begin{array}{l}\text { Form of evaluation: Calculation of the } \\
\text { revenue generated by a project divided by } \\
\text { the total cost of the project. }\end{array}$ \\
\hline
\end{tabular}

Table 2 - Subjective criteria.

\begin{tabular}{|c|c|c|}
\hline $\begin{array}{l}\text { 1. Degree of matriciality in } \\
\text { the use of SEBRAE/RJ } \\
\text { products in the project }\end{array}$ & $\begin{array}{l}\text { Projects which use the largest set of } \\
\text { SEBRAE/RJ Products tend to produce a } \\
\text { greater impact and be more important. }\end{array}$ & $\begin{array}{l}\text { Evaluation in } \\
\text { the scale } 1-5 \\
\text { (Worst - Best) }\end{array}$ \\
\hline $\begin{array}{l}\text { 2. Capacity to contribute to } \\
\text { the sustainable } \\
\text { development of the } \\
\text { Region. }\end{array}$ & $\begin{array}{l}\text { Seeking to measure the capacity of the } \\
\text { Project to create socio-economic leverage } \\
\text { in the Region and/or priority Sectors. }\end{array}$ & $\begin{array}{l}\text { Evaluation in } \\
\text { the scale } 1-5 \\
\text { (Worst - Best) }\end{array}$ \\
\hline $\begin{array}{l}\text { 3. Capacity to interact with } \\
\text { other sectors of the } \\
\text { economy }\end{array}$ & $\begin{array}{l}\text { Projects which interact with more than one } \\
\text { sector of the economy creating greater } \\
\text { opportunities for diverse sectors of the } \\
\text { economy. }\end{array}$ & $\begin{array}{l}\text { Evaluation in } \\
\text { the scale } 1-5 \\
\text { (Worst }- \text { Best) }\end{array}$ \\
\hline $\begin{array}{l}\text { 4. Capacity to create } \\
\text { employment and income }\end{array}$ & $\begin{array}{l}\text { Evaluating how much the project would } \\
\text { contribute to creating employment and an } \\
\text { increase in income for the community / } \\
\text { Productive Sector. }\end{array}$ & $\begin{array}{l}\text { Evaluation in } \\
\text { the scale } 1-5 \\
\text { (Worst - Best) }\end{array}$ \\
\hline $\begin{array}{l}\text { 5. Degree of adherence of } \\
\text { the partnerships in the } \\
\text { management/governance } \\
\text { of the Project }\end{array}$ & $\begin{array}{l}\text { Projects which act together with economic } \\
\text { forces in the locality achieve a greater } \\
\text { impact. }\end{array}$ & $\begin{array}{l}\text { Evaluation in } \\
\text { the scale } 1-5 \\
\text { (Worst }- \text { Best) }\end{array}$ \\
\hline 6. Risk of failure & $\begin{array}{l}\text { Evaluating the risk of the project not being } \\
\text { successful, taking into account all of the } \\
\text { effort of investment of resources and hours } \\
\text { worked. }\end{array}$ & $\begin{array}{l}\text { Evaluation in } \\
\text { the scale } 1-5 \\
\text { (Worst - Best) }\end{array}$ \\
\hline $\begin{array}{l}\text { 7. Degree of visibility that } \\
\text { the Project would bring to } \\
\text { SEBRAE/RJ }\end{array}$ & $\begin{array}{l}\text { Evaluating the impact that the project } \\
\text { provides in terms of visibility of actions } \\
\text { and reinforcement of the institutional } \\
\text { image of SEBRAE/RJ. }\end{array}$ & $\begin{array}{l}\text { Evaluation in } \\
\text { the scale } 1-5 \\
\text { (Worst - Best) }\end{array}$ \\
\hline
\end{tabular}


Table 3 shows the decision matrix, with the consequences of every project with respect to every evaluation criteria. Since the performances of all alternative projects with respect to criteria 8 (Risk of failure) and 9 (Degree of visibility that the project would bring to SEBRAE/RJ) are the same (and equal to 10), criteria 8 and 9 are not shown in Table 3. However, since this is not typical of other regions of Brazil managed by SEBRAE, it was decided that these two criteria should also appear in the decision matrix.

Table 3 - Decision Matrix.

\begin{tabular}{|c|c|c|c|c|c|c|c|}
\hline \multirow{2}{*}{ Projects } & \multicolumn{7}{|c|}{ Criteria } \\
\cline { 2 - 8 } & $\mathrm{C}_{1}$ & $\mathrm{C}_{2}$ & $\mathrm{C}_{3}$ & $\mathrm{C}_{4}$ & $\mathrm{C}_{5}$ & $\mathrm{C}_{6}$ & $\mathrm{C}_{7}$ \\
\hline$P_{1}$ & 775.79 & 0.083 & 4.00 & 10.00 & 10.00 & 8.00 & 10.00 \\
\hline$P_{2}$ & 393.06 & 0.061 & 6.00 & 10.00 & 8.00 & 10.00 & 8.00 \\
\hline$P_{3}$ & 343.93 & 0.628 & 4.00 & 10.00 & 10.00 & 10.00 & 10.00 \\
\hline$P_{4}$ & $1,572.24$ & 0.100 & 6.00 & 8.00 & 10.00 & 8.00 & 10.00 \\
\hline$P_{5}$ & 327.55 & 0.102 & 6.00 & 10.00 & 10.00 & 10.00 & 8.00 \\
\hline$P_{6}$ & 884.38 & 0.192 & 8.00 & 6.00 & 10.00 & 6.00 & 10.00 \\
\hline$P_{7}$ & $15,117.73$ & 0.092 & 0.00 & 10.00 & 10.00 & 10.00 & 10.00 \\
\hline$P_{8}$ & 884.39 & 0.096 & 4.00 & 10.00 & 8.00 & 10.00 & 8.00 \\
\hline$P_{9}$ & 929.54 & 0.122 & 0.00 & 10.00 & 10.00 & 10.00 & 10.00 \\
\hline$P_{10}$ & 982.67 & 0.305 & 6.00 & 10.00 & 10.00 & 8.00 & 8.00 \\
\hline$P_{11}$ & $3,684.94$ & 0.064 & 4.00 & 10.00 & 10.00 & 10.00 & 10.00 \\
\hline
\end{tabular}

\subsection{Application of ELECTRE IV}

The initial step in the application of ELECTRE IV consisted of setting the parameters of the methods. Those are presented in Table 4.

Table 4 - Preference and Indifference Thresholds of the Criteria.

\begin{tabular}{|c|c|c|c|c|c|}
\hline Criteria & $-\mathrm{p}$ & $-\mathrm{q}$ & 0 & $+\mathrm{q}$ & $+\mathrm{p}$ \\
\hline $\mathrm{C}_{1}$ & $-8,671.97$ & $-4,335.98$ & 0.00 & $4,335.98$ & $8,671.97$ \\
\hline $\mathrm{C}_{2}$ & -0.3360 & -0.1680 & 0.0 & 0.1680 & 0.3360 \\
\hline $\mathrm{C}_{3}$ & -3 & -1 & 0 & +1 & +3 \\
\hline $\mathrm{C}_{4}$ & -3 & -1 & 0 & +1 & +3 \\
\hline $\mathrm{C}_{5}$ & -3 & -1 & 0 & +1 & +3 \\
\hline $\mathrm{C}_{6}$ & -3 & -1 & 0 & +1 & +3 \\
\hline $\mathrm{C}_{7}$ & -3 & -1 & 0 & +1 & +3 \\
\hline $\mathrm{C}_{8}$ & -3 & -1 & 0 & +1 & +3 \\
\hline $\mathrm{C}_{9}$ & -3 & -1 & 0 & +1 & +3 \\
\hline
\end{tabular}

The rules of dominance were applied to all the projects to define the scoring reached at each comparison. When the scoring had been defined, a comparative matrix of the projects was prepared, which aided the definition of the ranking of each project. That matrix is presented in Table 5. 
Table 5 - Matrix of Credibility of the Projects.

\begin{tabular}{|c|c|c|c|c|c|c|c|c|c|c|c|}
\hline & $P_{1}$ & $P_{2}$ & $P_{3}$ & $P_{4}$ & $P_{5}$ & $P_{6}$ & $P_{7}$ & $P_{8}$ & $P_{9}$ & $P_{10}$ & $P_{11}$ \\
\hline$P_{1}$ & 0.4 & 0.4 & 0 & 0.4 & 0.4 & 0 & 0.8 & 0.4 & 0.4 & 0.4 & 0.4 \\
\hline$P_{2}$ & 0.4 & 0.4 & 0 & 0.4 & 0.4 & 0.4 & 0.4 & 0.8 & 0.4 & 0.4 & 0.4 \\
\hline$P_{3}$ & 0.8 & 0.8 & 0.4 & 0.8 & 0.8 & 0 & 0.8 & 0.8 & 0.8 & 0.4 & 0.8 \\
\hline$P_{4}$ & 0.4 & 0.4 & 0 & 0.4 & 0.4 & 0.4 & 0.4 & 0.4 & 0.4 & 0.4 & 0.4 \\
\hline$P_{5}$ & 0.4 & 0.8 & 0 & 0.4 & 0.4 & 0.4 & 0.8 & 0.8 & 0.4 & 0.4 & 0.4 \\
\hline$P_{6}$ & 0 & 0 & 0 & 0.4 & 0 & 0.4 & 0 & 0 & 0 & 0 & 0 \\
\hline$P_{7}$ & 0 & 0 & 0 & 0 & 0 & 0 & 0.4 & 0 & 0 & 0 & 0 \\
\hline$P_{8}$ & 0.4 & 0.4 & 0 & 0.4 & 0.4 & 0 & 0.4 & 0.4 & 0.4 & 0.4 & 0.4 \\
\hline$P_{9}$ & 0 & 0 & 0 & 0 & 0 & 0 & 0.8 & 0 & 0.4 & 0 & 0 \\
\hline$P_{10}$ & 0.4 & 0.4 & 0.4 & 0.4 & 0.4 & 0.4 & 0.8 & 0.4 & 0.4 & 0.4 & 0.4 \\
\hline$P_{11}$ & 0.8 & 0.4 & 0 & 0.4 & 0.4 & 0 & 0.8 & 0.8 & 0.8 & 0.4 & 0.4 \\
\hline
\end{tabular}

The ranking obtained and validated through a sensitivity analysis considers the greater quantity of victories obtained by the projects. In this way, we arrive at the following ordering by ELECTRE IV: $P_{3} \succ P_{5} \succ P_{2} \succ P_{11} \succ P_{10} \succ P_{1} \succ P_{4} \succ P_{8} \succ P_{9} \succ P_{6} \succ P_{7}$.

\subsection{Application of TODIM}

The data used in the application of TODIM were essentially the same of ELECTRE IV. In principle, the key differences in terms of necessary data are: (i) TODIM does not make use of preference and indifference thresholds as ELECTRE IV does; and (ii) when TODIM is used weights of criteria were required. However, in order to be able to comparer the applications of the two methods it was decided to treat these weights as having the same value. In the application of TODIM the attenuation factor for the losses, $\theta$, was made equal to one. The following ordering was then obtained by using TODIM: $P_{3} \succ P_{10} \succ P_{11} \succ P_{7} \succ P_{4}$ $\succ P_{5} \succ P_{9} \succ P_{1} \succ P_{6} \succ P_{8} \succ P_{2}$.

A sensitivity analysis on the results obtained from making use of TODIM confirmed the overall best positioning of $\mathrm{P}_{3}$, while $\mathrm{P}_{2}, \mathrm{P}_{8}$ and $\mathrm{P}_{1}$ were placed at the tale of the ranking.

\section{Discussion and Conclusions}

The fact that the two rankings that were obtained by different methods were different may be understood as a consequence from the different calculations performed by each method. On the other hand, it cannot be ignored that the same alternative project ranked as the best option in the application of each method. This fact suggests that even two MCDA methods based on different notions - the notion of outranking, in the case of ELECTRE IV, and the paradigm of Prospect Theory, in the case of TODIM - can lead to the same overall result.

While the same project was chosen as the best alternative from the application of each of the two methods, the project showing the wors performance were different in each case: P7 was selected as the worst project from the application of ELECTRE IV and P2 was found to be the worst project from the use of TODIM. 
As a matter of fact, ELECTRE IV and TODIM are not entirely different. Roy \& Bouyssou (1993), talking about the TODIM method, observed that this is: “...a method based on the French School and the American School. It combines aspects of the Multiattribute Utility Theory, of the AHP method and the ELECTRE methods" (p. 638). At the same time, the concept of introducing expressions of losses and gains in the same multiattribute value function makes TODIM similar to the PROMÉTHÉE methods, which make use of the notion of net outranking flow. Barba-Romero \& Pomerol (1997) have stated the following in respect of the TODIM method: "it is based on a notion extremely similar to a net flow, in the PROMÉTHÉE sense” (p. 229).

In essence, what the SEBRAE/RJ case study showed was that the correct use of an MCDA method, as long as it follows a comprehensive structuring of the decision problem, can clarify the process. This is indeed the key mission of decision aiding (Roy \& Bouyssou, 1993).

\section{Acknowledgements}

A Lemann Visiting Scholarship allowed the second author to work on this paper while at the University of Illinois (UIUC), in the Fall of 2008. He therefore thanks Werner Baer (Dept. of Economics) and Geoffrey Hewings (Regional Economics Applications Laboratory) of UIUC. The authors thank the National Council for Scientic and Technological Development (CNPq) of Brazil for supporting this research, Process No.306658/2004-6.

\section{References}

(1) Barba-Romero, S. \& Pomerol, J.C. (2000). Multicriterion Decision in Management: principles and practice. Kluwer Academic Publishers, Boston.

(2) Belton, V. \& Stewart, T.J. (2002). Multiple criteria decision analysis: an integrated approach. Kluwer Academic Publishers, Massachusetts.

(3) Bouyssou, D.; Jacquet-Lagrèze, E.; Perny, P.; Slowinski, R.; Vanderpooten, D. \& Vincke, P. (2002). Aiding decisions with multiple criteria. Kluwer Academic Press, Boston.

(4) Bouyssou, D.; Marchant, T.; Pirlot, M.; Perny, P.; Tsoukiàs, A. \& Vincke, P. (2000). Evaluation and decision models: a critical perspective. Kluwer Academic Press, Boston.

(5) Brans, J.P. \& Mareschal, B. (2002). PROMÉTHÉE-Gaia une méthodologie d'aide à la décision en presence de critères multiples. Éditions d l'Université de Bruxelles / Éditions Ellipses, Bruxelles.

(6) Brown, R.V. (2005). Rational choice and judgment: decision analysis for the decider. John Wiley \& Sons, New Jersey.

(7) Gomes, L.F.A.M. \& Lima, M.M.P.P. (1992a). TODIM: Basics and application to multicriteria ranking of projects with environmental impacts. Foundations of Computing and Decision Sciences, 16(4), 113-127.

(8) Gomes, L.F.A.M. \& Lima, M.M.P.P. (1992b) From Modeling Individual Preferences to Multicriteria Ranking of Discrete Alternatives: A look at Prospect Theory and the additive difference model. Foundations of Computing and Decision Sciences, 17(3), 171-184.

Pesquisa Operacional, v.29, n.3, p.577-590, Setembro a Dezembro de 2009 
(9) Gomes, L.F.A.M. \& Maranhão, F.J.C. (2008). A Exploração de Gás Natural em Mexilhão: Análise Multicritério pelo Método TODIM. Pesquisa Operacional, 28(3), 491-509.

(10) Gomes, L.F.A.M. \& Rangel, L.A.D. (2009). An application of the TODIM method to the multi-criteria rental evaluation of residential properties. European Journal of Operational Research, 193, 204-211. doi:10.1016/j.ejor.2007.10.046, <www.sciencedirect.com.>

(11) Goodwin, P. \& Wright, G. (2000). Decision analysis for management judgment. John Wiley \& Sons, Chichester.

(12) Hammond, J.S.; Keeney, R.L. \& Raiffa, H. (1999). Smart Choices. A practical guide to making better decisions. Harvard University School Press, Boston.

(13) Kahneman, D. \& Tversky, A. (1979). Prospect theory: An analysis of decision under risk. Econometrica, 47, 263-292.

(14) Keeney, R.L. \& Raiffa, H. (1999). Decisions with multiple objectives: preferences and value tradeoffs. Cambridge University Press, Cambridge.

(15) Moreira, R.A. \& Gomes, L.F.A.M. (2007). Uma análise multicritério de projetos de apoio social e econômico pelo método Electre IV. Manuscript under evaluation and submitted for publication in RAUSP.

(16) Moreira, R.A.; Gomes, L.F.A.M. \& Rangel, L.A.D. (2008). Using ELECTRE IV in the promotion of social and economic development: A case study in Rio de Janeiro. Manuscript under evaluation and submitted for publication in EJOR.

(17) Ozernoy, V.M. (1992). Choosing the "best” multiple criteria decision making method. INFOR, 30(2), 159-171.

(18) Raiffa, H. (2002). Decision Analysis: a Personal Account of How it Got Started and Evolved. Operations Research, 50(1), 179-185, Jan/Feb.

(19) Roy, B. \& Bouyssou, D. (1993). Aide multicritère à la décision: méthodes et cas. Economica, Paris.

(20) Roy, B. \& Hugonnard, J.C. (1982). Ranking of suburban line extension projects on the Paris Metro System by a multi-criteria method. Transportation Research, 16A, 301-312.

(21) Saaty, T.L. (1994). Fundamentals of Decision Making and Priority Theory with the Analytic Hierarchy Process, vol. VI. RWS, Pittsburgh.

(22) SEBRAE/RJ (2006a). Relatório de Atividades 2005. Serviço de Apoio às Micro e Pequenas Empresas / Estado do Rio de Janeiro, Rio de Janeiro.

(23) SEBRAE/RJ (2006b). Diretrizes para Elaboração do Plano Plurianual 2007/2009 e Orçamento 2007 do Sistema SEBRAE. Serviço de Apoio às Micro e Pequenas Empresas, Brasília.

(24) SEBRAE (2007). In: <http://www.sebrae.com.br/customizado/institucional/sebrae-umagente-de-desenvolvimento/BIA_1129/integra_bia>. Accessed on 21st November 2007. 